Available online on 15.01.2017 at http://iddtonline.info
C 2016, publisher and licensee JDDT, This is an Open Access article which permits unrestricted
noncommercial use, provided the original work is properly cited

Research Article

\title{
DESIGN AND DEVELOPMENT OF SIMVASTATIN GASTRORETENTIVE TABLETS FOR CONTROLLED RELEASE
}

\author{
N. G. Raghavendra Rao ${ }^{* 1}$, M. Laharika ${ }^{2}$, C. Kistayya ${ }^{3}$ \\ ${ }^{1}$ Sree Chaitanya Institute of Pharmaceutical Science, L.M.D. Colony, Thimmapur, Karimnagar - 505527, Telangana, India \\ ${ }^{2}$ Jyothishmathi institute of pharmaceutical sciences, Ramakrishna colony, Karimnagar -505481, Telangana, India \\ ${ }^{3}$ St. Johns College of Pharmaceutical Science, Yerrakota, Yemmiganur - 518360, Kurnool, Andhra Pradesh, India
}

\section{ABSTRACT}

Simvastatin is a Hypolipidemic used to control elevated cholesterol or hypercholesterolemia. The primary uses of simvastatin are for the treatment of dyslipidemia and the prevention of cardiovascular disease. Gastroretentive Floating tablets of Simvastatin were developed by direct compression method using HPMC K15M, HPMC K100M, Carbopol, sodium CMC, xanthan gum, sodium alginate polymers used and the mixture of the sodium bicarbonate, citric acid anhydrous as gas generating agents. The results of Precompressional and post compression parameters were within IP prescribed limits. The formulation FC1, FC2, FC3, FC4, FC5, FC6, FC8 floated but the lag time was more and floating time is less. For the formulation FC7, the duration of buoyancy was more than 12 hrs, the floating capacity increased in these formulations and floated with less lag time due to the high concentration of gas generating agent sodium bicarbonate-induced $\mathrm{CO}_{2}$ generation in the pressure of dissolution medium (pH 1.2 0.1N HCL). The drug release from the formulations FC1-FC8 was found to be 78.612, 72.66, 87.22, 63.45, 67.26, 73.24, 98.93, and 81.27 in $12 \mathrm{hrs}$. Among all the formulations FC7 floating lag time 7 min with $99 \%$ of drug release has better control release of the drug. DSC and FTIR studies revealed that there was no incompatibility of the drug with the excipients used. The stability study conducted as per the ICH guidelines and the formulations were found to be stable. From this study, it can be concluded that the formulation retained for longer periods of time in the stomach and provides controlled release of the drug and may improve bioavailability.

Keywords: Controlled Gastroretentive tablets, Simvastatin, HPMC, Carbopol.

Article Info

Received 22 Nov 2016; Review Completed 28 Dec 2016; Accepted 01 Jan 2017, Available online 15 Jan 2017

Cite this article as:

Nimker V, Jamal H, Ghosh PC, Jain S, Beotra A, Liposomes: drug delivery system or possible doping agent?, Journal of Drug Delivery and Therapeutics. 2017; 7(1):30-36, DOI: http://dx.doi.org/10.22270/iddt.v7i1.1353

*Corresponding author:

Dr. N. G. Raghavendra Rao

Principal and Professor, Sree Chaitanya Institute of Pharmaceutical Science, L.M.D. Colony, Thimmapur, Karimnagar- 505527, Telangana, India. Mob No: +919966794479, +919448570193, Email: ngraghu@rediffmail.com and drngraghu@gmail.com

\section{INTRODUCTION:}

Poor bioavailability has been recorded for some drugs formulated in sustained-release dosage forms. Their narrow absorption window, lower solubility at high $\mathrm{pH}$ values, or enzymatic degradation in the intestinal or colonic environments was the reason of decreased bioavailability ${ }^{1-5}$. For this, it has been a challenge to develop the oral controlled-release dosage form because it is difficult to keep drugs at the targeted area inside the gastrointestinal tract ${ }^{6}$. Gastro retentive drug delivery systems provide dosage forms with a longer residence time in the stomach and sustained-release behavior, which can improve bioavailability as well as the acting locally on the stomach ${ }^{7,8}$. Increasing gastric residence time can be achieved either by floating systems that 
cause buoyancy above gastric fluid ${ }^{9}$, high-density systems that sink to the bottom of the stomach $^{10}$, bioadhesive systems that adhere to mucosal surfaces ${ }^{11}$, or by expandable systems that have limited emptying through the stomach pylorus due to swelling or unfolding to a larger size $\mathrm{e}^{12}$.

The floating drug delivery systems were described in the literature as early as $1968^{13}$. These systems are designed to have a bulk density lower than the gastric fluid so they can remain buoyant for prolonged periods of time without affecting the gastric emptying rate ref $^{3,14}$. Floating drug delivery systems can be classified as noneffervescent systems or effervescent systems ${ }^{16}$. Noneffervescent floating drug delivery systems swell in gastric fluid and maintain a relative stability of shape and a bulk density less than the density of the gastric fluid, which assists the floating process of these dosage forms ${ }^{17}$. However, effervescent floating drug delivery systems based on effervescent components will liberate carbon dioxide due to the acidity of the gastric fluid. Liberated gas bubbles will be entrapped in the gel layer formed by hydrocolloids that produce an upward motion of the dosage form and maintain its buoyancy ${ }^{18}$.

Simvastatin is a Hypolipidemic used in management of elevated cholesterol or hypercholesterolemia. It is a member of the Statin class of pharmaceuticals. The primary uses of simvastatin are for the treatment of dyslipidemia and the prevention of cardiovascular disease. The $\mathbf{t}_{\mathbf{1} / \mathbf{2}}$ for Simvastatin is 2 to $4 \mathrm{hrs}$ and bioavailability is $5 \%$ and efficiency of protein binding is $95 \%$. This study provided valuable information on preformulation and formulation optimization of the selected anti-retroviral drugs as floating modules during the development of controlled drug delivery systems containing various rate controlling polymers, to get the desired controlled release over a period of $12 \mathrm{hrs}$. The main objective of the present research work is formulation and development of floating drug delivery system containing Simvastatin, which releases the drug at controlled rate for a long period of time in the stomach. The present investigation concerns the Gastroretentive tablets of Simvastatin were by direct compression technique using polymers like HPMC K15M, HPMC K100M, HPMC 5 cps, Carbopol, sodium
CMC, xanthan gum, sodium alginate polymers used and the mixture of sodium bicarbonate, citric acid anhydrous as gas generating agents, MCC, lactose as fillers.

\section{MATERIALS AND METHODS:}

Simvastatin drug is procured as a gift sample from Lupin labs, Private Ltd. Pune, India. HPMC K4M procured as a gift sample from AstraZeneca Pvt Ltd Bangalore. Carbopol 934, xanthan gum (XG), hydroxyl ethyl cellulose (HEC), magnesium stearate and citric acid are purchased from Hi media laboratories Pvt. Ltd, Mumbai. India, Sodium bicarbonate, sodium alginate, lactose, mannitol and talc were purchased from S.D. Fine Chemicals. Mumbai. All other materials used were of pharmaceutical grade.

Drug-excipients compatibility studies: Fourier Transform Infrared Spectroscopy (FTIR) and Differential Scanning Colorimetry.

Fourier Transform Infrared Spectroscopy (FTIR): FTIR studies were carried out pure drug Simvastatin and best formulations like, FC6 and FC7. Infrared spectroscopy was performed using a Shimadzu FTIR 8300 Spectrophotometer and the spectrum was recorded in the region of 4000 to $400 \mathrm{~cm}^{-1}$. The procedure consisted of dispersing a sample (drug and excipients, $1: 1$ ratio in potassium bromide $(\mathrm{KBr})(200-400 \mathrm{mg})$ and compressing into discs by applying a pressure of 5 tons for $5 \mathrm{~min}$ in a hydraulic press. The pellet was placed in the light path and the spectrum was obtained.

Differential Scanning Colorimetry: DSC studies were carried out pure drug Simvastatin and formulations like, FC6 and FC7. DSC scan of about 5mg accurately weighed Simvastatin and other formulations were performed by using an automatic thermal analyzer system. (DSC60 Shimadzu Corporation, Japan) Sealed and perforated aluminium pans were used in the experiments for all the samples. Temperature calibrations were performed using indium as standard. An empty pan sealed in the same way as for the sample was used as a reference. The entire samples were run at a scanning rate of $10^{\circ} \mathrm{C} / \mathrm{min}$ from $50-300^{\circ} \mathrm{C}$.

Table 1: Formulations of Simvastatin Floating tablets

\begin{tabular}{|l|l|l|l|l|l|l|l|l|}
\hline INGREDIENTS & FC1 & FC2 & FC3 & FC4 & FC5 & FC6 & FC7 & FC8 \\
\hline Drug & 40 & 40 & 40 & 40 & 40 & 40 & 40 & 40 \\
\hline Sodium bi carbonate & 40 & 40 & 40 & 40 & 50 & 50 & 60 & 50 \\
\hline Xanthan gum & 10 & 10 & 10 & 10 & 10 & 10 & 10 & 10 \\
\hline Sodium alginate & 10 & 10 & 10 & 10 & 10 & 10 & 10 & 10 \\
\hline Sodium CMC & 20 & 20 & 30 & 30 & 20 & 20 & 30 & 30 \\
\hline HPMC K15m & 20 & 30 & 20 & 30 & 20 & 30 & 20 & 30 \\
\hline HPMC K100m & 10 & 10 & 10 & 10 & 10 & 10 & 10 & 10 \\
\hline Citric acid & 5 & 5 & 5 & 5 & 5 & 5 & 5 & 5 \\
\hline Carbopol & - & - & - & - & 20 & 30 & 30 & 20 \\
\hline Talc & 10 & 10 & 10 & 10 & 10 & 10 & 10 & 10 \\
\hline Magnesium stearate & 10 & 10 & 10 & 10 & 10 & 10 & 10 & 10 \\
\hline MCC & 65 & 55 & 55 & 45 & 35 & 15 & 05 & 15 \\
\hline Total & 300 & 300 & 300 & 300 & 300 & 300 & 300 & 300 \\
\hline
\end{tabular}


Preparation of Simvastatin floating tablets ${ }^{19-20}$ : All the formulations FC1 to FC8 were prepared by direct compression method. The composition of the tablets is given in Table 1. All the formulation tablets containing drug and other excipients, were prepared by weighing drug, diluents along with natural gums and passing them through sieve no 44 to break the lumps and also for proper blending of powder, to this powder blend $0.5 \%$ of magnesium stearate and $1 \%$ of talc were added to each and further mixed. The resultant blends were punched to $300 \mathrm{mg}$ using convex-faced punches using a multi-station rotary compression machine (Rinek mini press-II MT).

The resultant blends were evaluated for precompressional parameters to find out the flow properties of powder blend. The pre-compressional parameters such as Bulk density, Tapped density, Angle of repose, Compressibility index and Hausner ratio.

\section{Evaluation of Simvastatin floating tablets ${ }^{21-24}$ :}

Weight Variation Test: Weigh 20 tablets selected at random and calculate the average weight. Not more than two of the individual weights deviate from the average weight by more than the percentage limits. As per Indian Pharmacopoeia specification.

Friability Test: 20 tablets were weighed and subjected to rotate on friability test apparatus. The drum rotated at a speed of $25 \mathrm{rpm}$ for 4 minutes, then dedusted and reweighed the tablets. Percentage friability was calculated. Percentage friability of tablets less than $1 \%$ is considered acceptable.

Hardness Test: The hardness of tablet was carried out by using Pfizer type hardness tester. The hardness of the tablet $\mathrm{kg} / \mathrm{cm}^{2}$ was measured.

Thickness Test: Control of physical dimension of the tablets such as sizes and thickness is essential for consumer acceptance and to maintain tablet to tablet uniformity. The dimensional specifications were measured using verniar calipers. Six tablets from each batch were tested and average values were calculated. The thickness of the tablet is mostly related to the tablet hardness can be uses as initial control parameter.

Buoyancy lag time (BLT): The time taken for dosage form to emerge on surface of medium is called floating lag time (FLT) or buoyancy lag time (BLT).

Determination of in-vitro floating lag time: The invitro buoyancy was determined by floating lag time and total floating time, as per the method. In a $250 \mathrm{ml}$ beaker containing buffer solution, maintained at $37 \pm 0.5^{\circ} \mathrm{C}$ in a water bath. Their physical state was observed for $24 \mathrm{~h}$. The time required for the tablet to rise to the surface and float was determined as floating lag time and total duration of time by which dosage form remain buoyant is called total floating time.

In-vitro dissolution studies: The release rate of Simvastatin from floating tablet was determined by Dissolution Tester apparatus DS-8050 Lab India. The dissolution test was performed using $900 \mathrm{ml} 0.1 \mathrm{~N} \mathrm{HCL}$ with $1 \%$ sodium lauryl sulphate at $37^{\circ} \mathrm{C} \pm 0.5^{\circ} \mathrm{C}$. At each hour interval, aliquots of $10 \mathrm{ml}$ were withdrawn from the dissolution medium and the amount was replaced with fresh medium to maintain the volume constant. The samples were filtered through a Whatmaan filter paper and diluted to a suitable concentration with dissolution media for the study. The absorbance of the solutions was measured at $236 \mathrm{~nm}$. Cumulative percentage of drug release was calculated using an equation obtained from the standard curve.

Determination of swelling index: The swelling index of tablets was determined in $0.1 \mathrm{~N} \mathrm{HCL}$ (with $1 \%$ SLS) at $37^{\circ} \mathrm{C}$ temperature. The swollen weight of the tablet was determined at predefined time intervals over a period of $5 \mathrm{hr}$. The swelling index (SI) is expressed as a percentage and was calculated from the following equation.

$$
\text { Swelling index }=\frac{\mathrm{W}_{2}-\mathrm{W}_{1}}{\mathrm{~W}_{1}} \times 100
$$

Stability Studies: Stability studies were performed on optimised formulation, prepared tablets were wrapped with aluminium foil and kept in a vial. These samples were placed in a stability chamber (Thermolab, humidity and photo stability chamber) at $40 \pm 2^{\circ} \mathrm{C}$ and $75 \pm 5 \% \mathrm{RH}$ according to $\mathrm{ICH}$ guidelines. At regular time intervals of 15, 30, 60 and 90 days tablets were analysed for drug release lag time.

\section{RESULTS AND DISCUSSIONS:}

\section{Drug - Excipient compatibility studies:}

FTIR Studies: The FT-IR spectra of pure drug peaks are observed in the Simvastatin sample and formulations were showed same characteristic absorption bands at or near that of Simvastatin absorption bands values indicating that there was no chemical and physical change in the functional groups present in Simvastatin. [Shown in Fig 1].

DSC Studies: The study also reveals that the thermogram of pure drug and other formulations [Shown in Fig 2] shows negligible changes in the melting point range. Thus the DSC thermograms study reveals that there is no any kind of interaction of the drug with different types of polymer and their excipients used during the study.

\section{Evaluation of Simvastatin gas powered tablets:}

The Pre-compression parameters were the primary requirements to determine whether the specific material was suitable for the targeted formulation or not. The aim was to formulate the tablet formulation with direct compression method, so it was mandatory to know the bulk density, tapped density, Carr's index, Hausner's ratio and angle of repose as those were the official requirement while choosing any material for its dosage form formulation. The results evaluated pre-compression parameters for various tablet formulations. The results clearly indicate its suitability to be the material of choice for formulation. The values were within prescribed limits and indicated good free-flowing property. The results of pre-compression parameters were given in Table 2. 


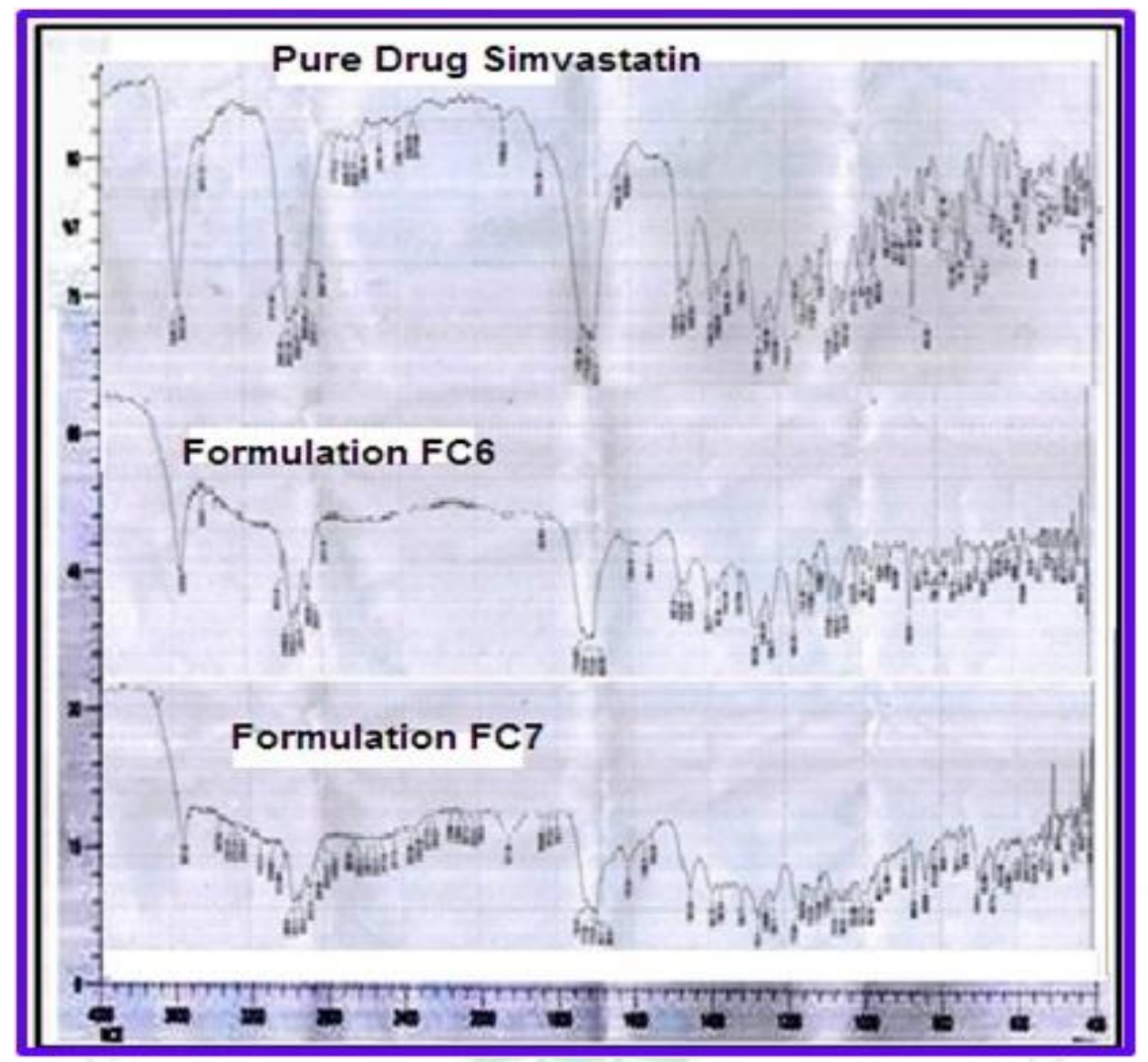

Figure 1: IR spectra of pure drug Simvastatin and optimized formulations FC6 and FC7.

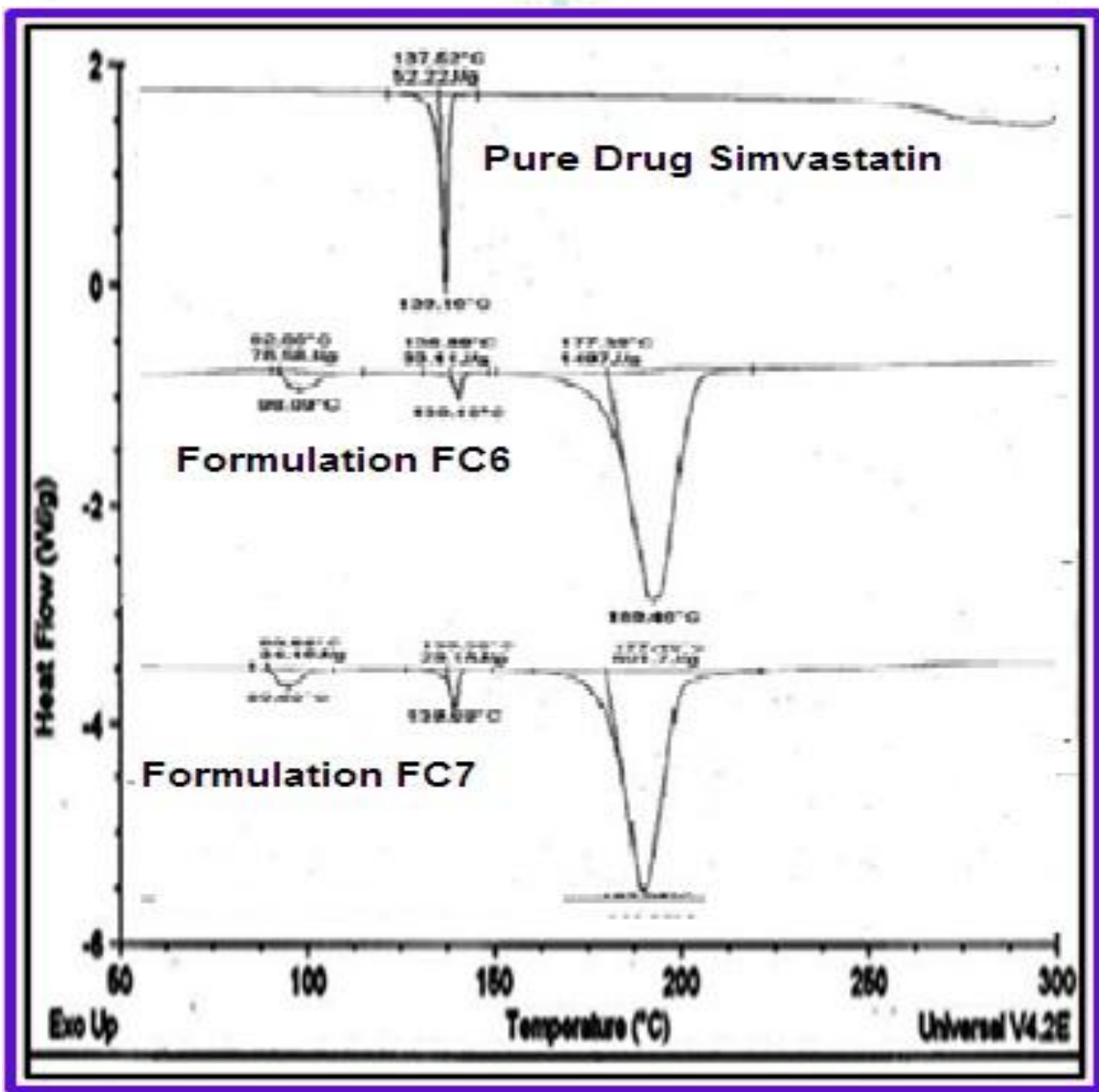

Figure 2: DSC Thermograms of pure drug Simvastatin and optimized formulations FC6 and FC7. 
Table 2: Evaluation of Pre-Compression Parameters (FC1-FC8)

\begin{tabular}{|l|l|l|l|l|l|}
\hline FC & $\begin{array}{l}\text { Angle of } \\
\text { repose } \mathbf{(}^{\left(\mathbf{~}^{*}\right.}\end{array}$ & $\begin{array}{l}\text { Bulk } \\
\text { density }\left(\mathbf{g m} / \mathbf{c m}^{\mathbf{3}}\right)^{*}\end{array}$ & $\begin{array}{l}\text { Tapped } \\
\text { density }\left(\mathbf{g m} / \mathbf{c m}^{\mathbf{3}}\right)^{*}\end{array}$ & Carr's Index (\%)* & $\begin{array}{l}\text { Hausner ratio } \\
(\mathbf{H r})^{*}\end{array}$ \\
\hline FC1 & $28^{0} .05^{\prime} \pm 0.12$ & $0.462 \pm 0.03$ & $0.56 \pm 0.01$ & $12.64 \pm 0.05$ & $1.13 \pm 0.06$ \\
\hline FC2 & $28^{0} .24^{\prime} \pm 0.11$ & $0.546 \pm 0.01$ & $0.67 \pm 0.02$ & $21.62 \pm 0.06$ & $1.24 \pm 0.04$ \\
\hline FC3 & $26^{0} .84^{\prime} \pm 0.12$ & $0.528 \pm 0.02$ & $0.54 \pm 0.04$ & $18.36 \pm 0.05$ & $1.22 \pm 0.06$ \\
\hline FC4 & $28^{0} .24^{\prime} \pm 0.15$ & $0.468 \pm 0.04$ & $0.64 \pm 0.03$ & $25.36 \pm 0.04$ & $1.32 \pm 0.04$ \\
\hline FC5 & $28^{0} .36^{\prime} \pm 0.14$ & $0.448 \pm 0.02$ & $0.54 \pm 0.04$ & $22.24 \pm 0.05$ & $1.24 \pm 0.08$ \\
\hline FC6 & $29^{0} .22^{\prime} \pm 0.12$ & $0.346 \pm 0.06$ & $0.66 \pm 0.05$ & $11.64 \pm 0.04$ & $1.14 \pm 0.06$ \\
\hline FC7 & $29^{0} .34^{\prime} \pm 0.12$ & $0.532 \pm 0.04$ & $0.56 \pm 0.06$ & $11.46 \pm 0.02$ & $1.16 \pm 0.02$ \\
\hline FC8 & $28^{0} .05^{\prime} \pm 0.13$ & $0.462 \pm 0.04$ & $0.46 \pm 0.02$ & $12.64 \pm 0.06$ & $1.13 \pm 0.07$ \\
\hline
\end{tabular}

$\mathrm{FC}=$ Formulation code $*$ All the values expressed as mean $\pm \mathrm{SD}, \mathrm{n}=3$

All the prepared batches were evaluated systematically. The obtained results of the evaluated post compression parameters were represented in in Table 3. The results of all the trial batches were compared and found satisfactory, as per the reported specification. Finally, the comparison parameters were keenly observed to finalize for selection of the optimized batch and formula. The results of Postcompressional parameters were within I.P prescribed limits.

Water Uptake Study (Swelling Index): Tablets composed of polymeric matrices build a gel layer around tablets core when they come in contact with water. This gel layer governs the drug release. Kinetics of swelling is important because the gel barrier is formed with water permeation. Swelling is also a vital factor to ensure floating. To obtain floating the balance between swelling and water acceptance must be restored. ${ }^{101}$ Results of water uptake study showed that the order of swelling in these polymers could indicate the rates at which the preparations are able to absorb water and swell. Maximum liquid uptake and swelling of the polymer achieved up to $7 \mathrm{hrs}$ and then gradually decreased due to erosion. The swelling of polymers used in this CGPS tablets (HPMC K4M, carbopol, sodium CMC, sodium alginate) could be determined by water uptake of the tablets. The complete swelling was achieved by the end of $7 \mathrm{hrs}$.

Table 3: Evaluation of Post Compression Parameters (FC1-FC8)

\begin{tabular}{|l|l|l|l|l|l|l|}
\hline FC & $\begin{array}{l}\text { Thickness } \\
(\mathbf{m m}) *\end{array}$ & $\begin{array}{l}\text { Hardness } \\
\left(\mathbf{k g} / \mathbf{c m}^{2}\right)\end{array}$ & $\begin{array}{l}\text { Friability } \\
(\boldsymbol{\%})^{*}\end{array}$ & $\begin{array}{l}\text { Drug content } \\
(\boldsymbol{\%}) *\end{array}$ & $\begin{array}{l}\text { Weight } \\
\text { variation }(\mathbf{m g}) * *\end{array}$ & $\begin{array}{l}\text { Swelling index } \\
(\boldsymbol{\%}) * *\end{array}$ \\
\hline FC1 & $4.06 \pm 0.056$ & $6.3 \pm 0.2$ & $0.61 \pm 0.07$ & 83.65 & $299.66 \pm 1.52$ & $78.42 \pm 0.45$ \\
\hline FC2 & $4.17 \pm 0.057$ & $6.5 \pm 0.3$ & $0.64 \pm 0.09$ & 83.01 & $301.33 \pm 2.51$ & $98.20 \pm 0.63$ \\
\hline FC3 & $4.14 \pm 0.140$ & $6.4 \pm 0.1$ & $0.65 \pm 0.10$ & 76.6 & $301.33 \pm 2.08$ & $110.40 \pm 0.92$ \\
\hline FC4 & $4.28 \pm 0.206$ & $6.3 \pm 0.1$ & $0.60 \pm 0.03$ & 79.16 & $300.00 \pm 2.00$ & $108.20 \pm 0.45$ \\
\hline FC5 & $4.23 \pm 0.102$ & $6.2 \pm 0.3$ & $0.64 \pm 0.12$ & 84.61 & $302.00 \pm 1.00$ & $96.40 \pm 0.23$ \\
\hline FC6 & $4.22 \pm 0.021$ & $6.2 \pm 0.1$ & $0.60 \pm 0.11$ & 87.17 & $299.00 \pm 1.00$ & $102.10 \pm 0.25$ \\
\hline FC7 & $4.19 \pm 0.036$ & $6.5 \pm 0.1$ & $0.64 \pm 0.13$ & 89.42 & $303.66 \pm 1.50$ & $95.76 \pm 0.54$ \\
\hline FC8 & $4.20 \pm 0.040$ & $6.6 \pm 0.1$ & $0.69 \pm 0.10$ & 79.8 & $301.66 \pm 2.08$ & $104.48 \pm 0.20$ \\
\hline
\end{tabular}

$\mathrm{FC}=$ Formulation code, $* *$ All the values expressed as mean $\pm \mathrm{SD}, \mathrm{n}=20$,

$*$ All the values expressed as mean $\pm \mathrm{SD}, \mathrm{n}=3$

In-Vitro Buoyancy and Lag Time Study: The formulation FC1, FC2, FC3, FC4, FC5, FC6, FC8 floated but the lag time was more and floating time is less. For the formulation FC7, the duration of buoyancy was more than $12 \mathrm{hrs}$, the floating capacity increased in these formulations and floated with less lag time due to the high concentration of gas generating agent sodium bicarbonate-induced $\mathrm{CO}_{2}$ generation in the pressure of dissolution medium ( $\mathrm{pH} \quad 1.2 \quad 0.1 \mathrm{~N} \quad \mathrm{HCL})$. The gas generation is trapped \& protected within the gel formed by hydration of the polymers, thus decreasing the density of tablet. As the amount of polymer in the tablet formulation increases, the drug release rate decreases and as the concentration of gas generating agent $\left(\mathrm{NaHCO}_{3}\right)$ increases the drug release increases and at the same time floating lags time decreases. All the results were given in Fig 3.
In-vitro Drug Release Studies of Simvastatin Formulations: The drug release from the formulations FC1-FC8 was found to be $78.612,72.66,87.22,63.45$, $67.26,73.24,98.93$, and 81.27 in $12 \mathrm{hrs}$. Among all the formulations FC7 formulation shows the drug release around $98.93 \%$ within $12 \mathrm{hrs}$. From the in-vitro drug release study, it is found to be as the concentration of the polymer increases the drug release decreases. The dissolution profiles of all the formulations are shown in Fig 4-5. From results the formulation containing the large concentration of high viscosity polymers induced the formation of strong viscous gel layer that leads to decreased water diffusion into the tablet which results in decrease drug release. 


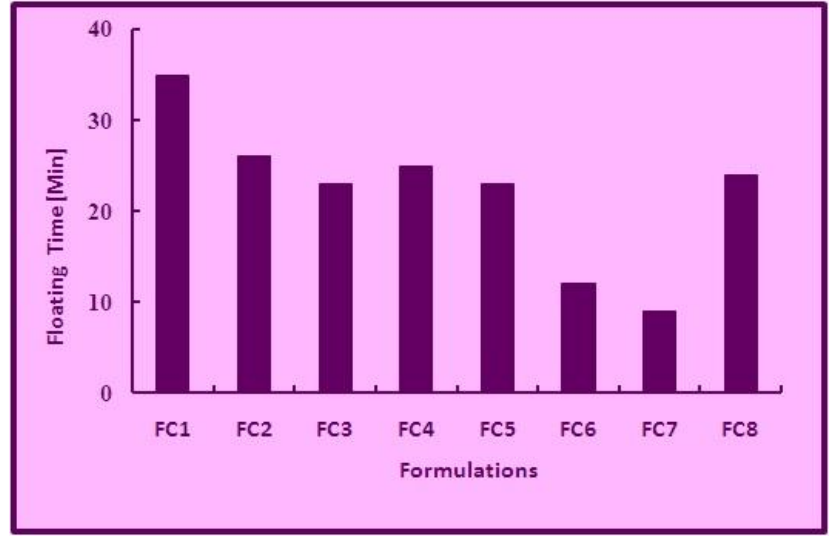

Figure 3: Floating Time Vs Formulation FC1-FC8

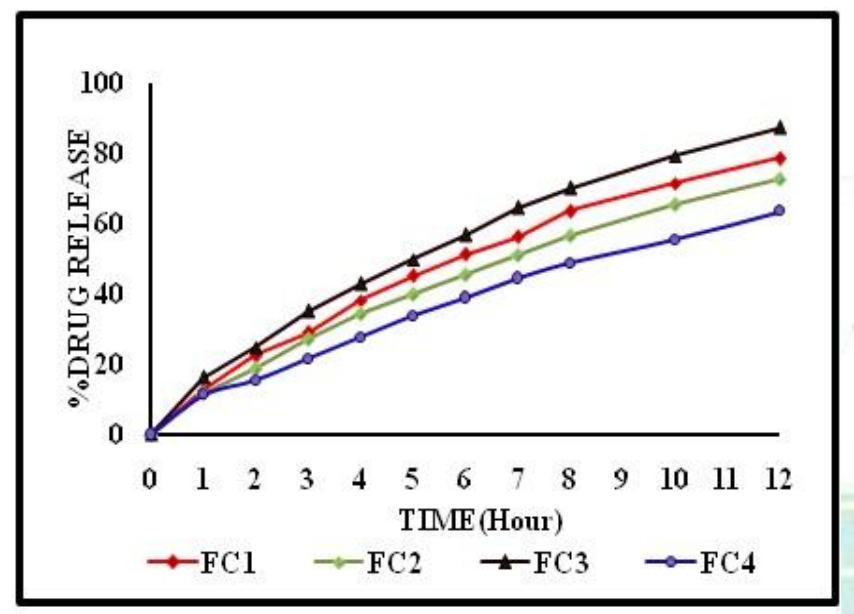

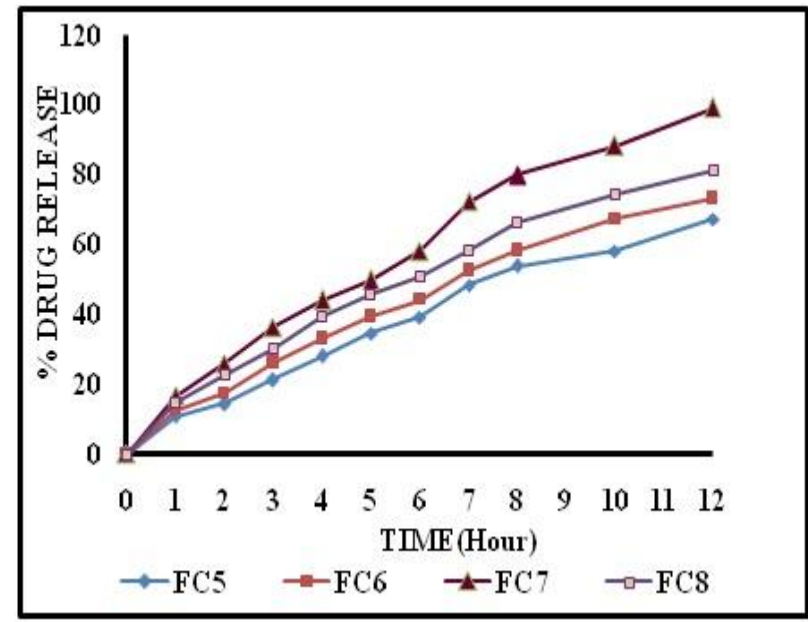

Figure 5: Release profile of formulations FC5-FC8

In-vitro drug release kinetic studies: A result showed in table 4 reveals that all formulations follow zero order kinetics as correlation coefficient $\left(\mathrm{r}^{2}\right)$ values are higher than that of first order release kinetics. The calculated $n$ values from power law equation for drug release profiles were between $0.870-0.997$ with a correlation coefficient $\left(\mathrm{r}^{2}\right)$ values $>0.94$, suggest that drug release mechanism from Simvastatin Floating tablets followed non-Fickian (anomalous) transport mechanism.

Figure 4: Release profile of formulations FC1-FC4

Table 4: In-vitro Drug release kinetics of FC1-FC8 Formulation

\begin{tabular}{|l|l|l|l|l|l|}
\hline FC & Zero Order $\mathbf{R}^{\mathbf{2}}$ Value & First Order $\mathbf{R}^{\mathbf{2}}$ Value & Higuchi $\mathbf{R}^{\mathbf{2}}$ Value & Peppas $\mathbf{R}^{\mathbf{2}}$ Value & Peppas n value \\
\hline FC1 & 0.975 & 0.997 & 0.975 & 0.996 & 0.746 \\
\hline FC2 & 0.982 & 0.998 & 0.973 & 0.998 & 0.748 \\
\hline FC3 & 0.976 & 0.987 & 0.981 & 0.997 & 0.700 \\
\hline FC4 & 0.987 & 0.997 & 0.964 & 0.989 & 0.737 \\
\hline FC5 & 0.979 & 0.991 & 0.950 & 0.985 & 0.795 \\
\hline FC6 & 0.983 & 0.994 & 0.963 & 0.991 & 0.752 \\
\hline FC7 & 0.981 & 0.816 & 0.962 & 0.994 & 0.739 \\
\hline FC8 & 0.980 & 0.992 & 0.974 & 0.996 & 0.713 \\
\hline
\end{tabular}

$\mathrm{FC}=$ Formulation code

Table 5 shows the parameters of the tablets after stability study. The promising formulations were subjected to short-term stability study. The best formulations were selected. After three months the tablets were again analyzed for the hardness, drug content uniformity and floating time. No significant changes in other parameters were observed in the tablets prepared with the different technique of all formulations was within the acceptable limits.

Table 5: Stability study data

\begin{tabular}{|l|l|l|l|l|l|}
\hline S. N. & FC & Month & Hardness $\mathbf{( K g / \mathbf { c m } ^ { 2 } )}$ & Drug Content $\mathbf{( \% )}$ & Floating Lag Time \\
\hline \multirow{3}{*}{2} & \multirow{2}{*}{ FC7 } & $\mathbf{1}^{\text {st }}$ & 6.7 & 87.48 & $07 \mathrm{~min} 34 \mathrm{sec}$ \\
\cline { 3 - 6 } & & $\mathbf{2}^{\text {nd }}$ & 6.7 & 88.59 & $07 \mathrm{~min} 55 \mathrm{sec}$ \\
\cline { 3 - 6 } & $\mathbf{3}^{\text {rd }}$ & 6.9 & 85.41 & $8 \mathrm{~min}$ \\
\hline
\end{tabular}

$\mathrm{FC}=$ Formulation code 


\section{CONCLUSION:}

Studies have been carried out to develop Gastroretentive tablets of Simvastatin with natural polymers HPMC K15M, HPMC100M, xanthan gum, Carbopol. The powder blend was evaluated for various Micromeritic properties. Eight different formulations were made and the formulations were tested for floating characterization like floating lag time and floating time, in-vitro dissolution studies. Based on the results of floating and dissolution studies FC7 formulation shows the drug release around $99 \%$ within $12 \mathrm{hrs}$. FC7 was found to be the best among trials. The formula FC7 floating lag time 7 min with $99 \%$ of drug release has better control release of the drug. Finally, it can be concluded that the formulation retained for longer periods of time in the stomach (spatial control) and provides controlled release of the drug. Hence, Gastroretentive tablets retained for longer periods of time in the stomach which may lead to improves the therapeutic effect of the drug by increasing its bioavailability.

\section{REFERENCES:}

1. Hoffman A. Pharmacodynamic aspects of sustained release preparations. Adv Drug Deliv Rev. 1998; 33:185-199.

2. Baumgartner S, Kristl J, Vrecer F, Vodopivec P, Zorko B. Optimisation of floating matrix tablets and evaluation of their gastric residence time. Int J Pharm. 2000; 195:125-135.

3. Singh BN, Kim KH. Floating drug delivery systems: an approach to oral controlled drug delivery via gastric retention. J Control Release. 2000; 63(3):235-259.

4. Streubel A, Siepmann J, Bodmeier R. Drug delivery to the upper small intestine window using gastroretentive technologies. Curr Opin Pharmacol. 2006; 6:501-508.

5. Nayak AK, Maji R, Das B. Gastroretentive drug delivery systems: a review. Asian J Pharm Clin Res. 2010; 3:2-10.

6. Lee TW, Robinson JR. Controlled release drug delivery systems. In: Gennaro AR, editor. The Science and Practice of Pharmacy. Vol I. 20th ed. Remington: Mack Publishing Company; 2000:1676-1693.

7. Kagan L, Lapidot N, Afargan M, et al. Gastroretentive accordion pill: enhancement of riboflavin bioavailability in humans. J Control Release. 2006; 113:208-215.

8. Murphy CS, Pillay V, Choonara YE, Du Toit LC. Gastroretentive drug delivery systems: current developments in novel system design and evaluation. Curr Drug Deliv. 2009; 6:451-460

9. Xiaoqiang X, Minjie S, Feng Z, Yiqiao H. Floating matrix dosage form for phenoporlamine hydrochloride based on gas forming agent: in vitro and in vivo evaluation in healthy volunteers. Int J Pharm. 2006; 310:139-145.
10. Hwang SJ, Park H, Park K. Gastric retentive drug-delivery systems. Crit Rev Ther Drug Carrier Syst. 1998; 15(3):243284.

11. Chavanpatil MD, Jain P, Chaudhari S, Shear R, Vavia RR. Novel sustained release, swellable and bioadhesive gastroretentive drug delivery system for ofloxacin. Int $J$ Pharm. 2006; 316(1-2):86-92.

12. Deshpande AA, Shah NH, Rhodes CT, Malick W. Development of a novel controlled release system for gastric retention. Pharm Res. 1997; 14:815-819.

13. Davis DW. Method of swallowing a pill. US Patent. 1968; 3(418):999.

14. Rouge N, Buri P, Doelker E. Drug absorption sites in the gastrointestinal tract and dosage forms for site-specific delivery. Int J Pharm. 1996; 136:117-139.

15. Brahma N, Kwon HK. Floating drug delivery systems: an approach to oral controlled drug delivery via gastric retention. J Controlled Release. 2000; 63:235-259.

16. Seth PR, Tossounian J. The hydrodynamically balanced system, a novel drug delivery system for oral use. Drug Dev Ind Pharm. 1984; 10:313-339.

17. Hilton AK, Deasy PB. In vitro and in vivo evaluation of an oral sustained-release floating dosage form of amoxycillin trihydrate. Int J Pharm. 1992; 86(1):79-88.

18. Rubinstein A, Friend DR. Specific delivery to the gastrointestinal tract. In: Domb AJ, editor. Polymeric SiteSpecific Pharmacotherapy. Chichester: Wiley; 1994:282-283.

19. Raghavendra Rao NG, Vijaya Kumar G, Akhlaaq Ahmad. Formulation and Evaluation of Gas Powered System of captopril tablets. American Journal of Pharmacy and Health Resaerch. AJPHR: 2015; 3(9):40 - 56.

20. Raghavendra Rao NG, Vijaya Kumar G, Priyanka V. Design and Development of Niveripine Gas powered systems for controlled release. Asian Journal of Biochemical and Pharmaceutical Research. AJBPR. 2015; 5(3):146-157.

21. Raghavendra Rao NG, Sunil Firangi, Keyur Patel. Formulation And In-Vitro Evaluation Of Zidovudine Gastroretentive Floating Drug Delivery System For Prolong Release. International Journal of Current Biomedical and Pharmaceutical Research. IJCBPR: 2011; 1(4):226-233.

22. Raghavendra Rao NG, Sunil Firangi, Keyur Patel. Formulation and Evaluation Of Gastroretentive Effervescent Floating Drug Delivery System Of Zidovudine. American Journal of Pharma Tech Research. AJPTR: Feb: 2012; 2(1):513-529.

23. Raghavendra Rao NG, Shrishail Ghurghure. Formulation and Evaluation of Zidovudine Controlled Release Gas Powered System Using hydrophilic Polymer. International Research Journal of Pharmacy. IRJP 2 (3), March-2011:86-94.

24. Raghavendra Rao NG, Harsh A Panchal, Pentewar Ram. Formulation And In-Vitro Evaluation Gastroretentive Drug Delivery System Of Cefixime For Prolong Release. Der Pharmacia Sinica, 2011, 2 (2):236-248. 